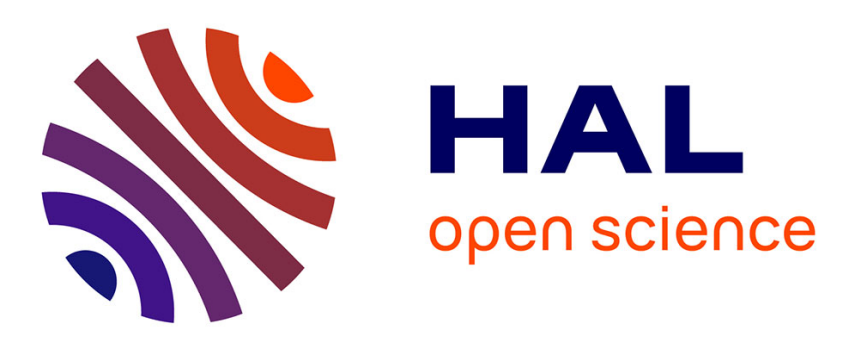

\title{
Time-varying correlations in oil, gas and CO2 prices: an application using BEKK, CCC, and DCC-MGARCH models
}

\author{
Julien Chevallier
}

\section{- To cite this version:}

Julien Chevallier. Time-varying correlations in oil, gas and CO2 prices: an application using BEKK, CCC, and DCC-MGARCH models. Applied Economics, 2011, pp.1. 10.1080/00036846.2011.589809 . hal-00716634

\section{HAL Id: hal-00716634 \\ https://hal.science/hal-00716634}

Submitted on 11 Jul 2012

HAL is a multi-disciplinary open access archive for the deposit and dissemination of scientific research documents, whether they are published or not. The documents may come from teaching and research institutions in France or abroad, or from public or private research centers.
L'archive ouverte pluridisciplinaire HAL, est destinée au dépôt et à la diffusion de documents scientifiques de niveau recherche, publiés ou non, émanant des établissements d'enseignement et de recherche français ou étrangers, des laboratoires publics ou privés. 


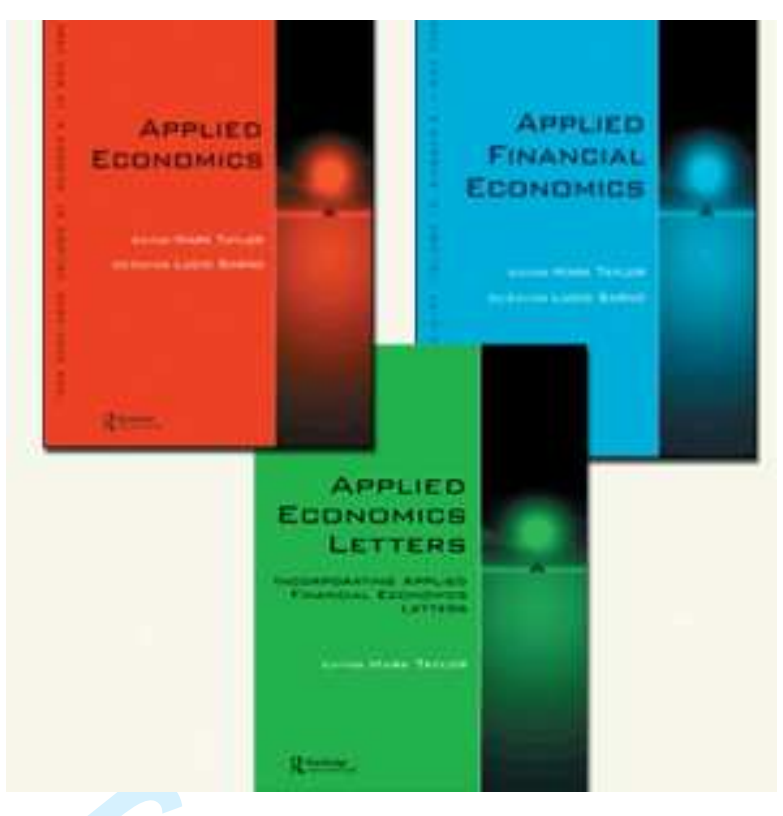

Time-varying correlations in oil, gas and $\mathrm{CO} 2$ prices: an application using BEKK, CCC, and DCC-MGARCH models

\begin{tabular}{|r|l|}
\hline Journal: & Applied Economics \\
\hline Manuscript ID: & APE-2009-0319.R1 \\
\hline Journal Selection: & Applied Economics \\
\hline $\begin{array}{r}\text { Date Submitted by the } \\
\text { Author: }\end{array}$ & 03-Nov-2010 \\
\hline JEL Code: & $\begin{array}{l}\text { C5 - Mathematical and Quantitative Methods, Q54 - Climate|Natural } \\
\text { Disasters < Q5 - Environmental Economics < Q - Agricultural and } \\
\text { Natural Resource Economics, Q40 - General < Q4 - Energy < Q - } \\
\text { Agricultural and Natural Resource Economics }\end{array}$ \\
\hline Keywords: & $\begin{array}{l}\text { Oil; Gas; CO2, BEKK, CCC, DCC MGARCH, EU ETS, Time-Varying } \\
\text { Correlation, Vector Autoregression }\end{array}$ \\
\hline \multicolumn{2}{|l}{} \\
\hline
\end{tabular}

\section{SCHOLARONE ${ }^{m}$ \\ Manuscripts}




\title{
Time-varying correlations in oil, gas and $\mathrm{CO}_{2}$ prices: an application using BEKK, CCC, and DCC-MGARCH models
}

\author{
Julien Chevallier ${ }^{1}$ \\ Université Paris Dauphine (CGEMP/LEDa)
}

\begin{abstract}
Previous literature has identified oil and gas prices as being the main drivers of $\mathrm{CO}_{2}$ prices in a univariate GARCH econometric framework (Alberola et al. (2008), Oberndorfer (2009)). By contrast, we argue in this article that the interrelationships between energy and emissions markets shall be modeled in a vector autoregressive and multivariate GARCH framework, so as to reflect the dynamics of the correlations between the oil, gas and $\mathrm{CO}_{2}$ variables overtime. Using BEKK, CCC, and DCC-MGARCH models on daily data from April 2005 to December 2008, we highlight significant own-volatility, cross-volatility spillovers, and own persistent volatility effects for nearly all markets, indicating the presence of strong ARCH and GARCH effects. Besides, we provide strong empirical evidence of time-varying correlations in the range of [-0.3;0.3] between oil and gas, $[-0.05 ; 0.05]$ between oil and $\mathrm{CO}_{2}$, and $[-0.2 ; 0.2]$ between gas and $\mathrm{CO}_{2}$, that have not been considered by previous studies. These findings are of interest for traders and utilities in the energy sector, but also for a broader applied economics audience.
\end{abstract}

JEL Classification: Q48; Q57; Q58.

Keywords: Oil; Gas; $\mathrm{CO}_{2}$; EU ETS; Vector Autoregression; Multivariate GARCH; Time-Varying Correlation; BEKK-MGARCH Model; CCC-MGARCH Model; DCC-MGARCH Model.

\footnotetext{
${ }^{1}$ Address for correspondence: Place du Maréchal de Lattre de Tassigny 75775 Paris Cedex 16, France. Email address: julien.chevallier@dauphine.fr
} 


\section{Introduction}

Statistical analyses of price determinants in the EU Emissions Trading Scheme (EU ETS) have so far relied on univariate $\mathrm{GARCH}^{2}$ models to explain the interrelationships between energy and emissions markets. Based on a standard $\operatorname{GARCH}(1,1)$ model, Alberola et al. (2008) identify oil and gas as being the main $\mathrm{CO}_{2}$ price drivers. High (low) energy prices contribute to an increase (decrease) of $\mathrm{CO}_{2}$ prices $^{3}$. Oberndorfer (2009) develops an empirical analysis of stock market effects in the EU ETS. Based also on a GARCH(1,1) model with oil, gas, and electricity volatility variables in the variance equation, the author identifies a positive relationship between $\mathrm{CO}_{2}$ prices and stock returns in the electricity sector.

This article focuses on the contemporaneous interrelationships between energy (oil, gas) and emissions $\left(\mathrm{CO}_{2}\right)$ markets ${ }^{4}$. The directions of these links are in essence complex to capture. The EU ETS is a commodity market, which is influenced by other factors as well, notably fuel shifts and energy efficiency. The $\mathrm{CO}_{2}$ price is determined by the demand and supply of $\mathrm{CO}_{2}$ rights - a surplus induced by above-mentioned measures or reduced energy demand would reduce the $\mathrm{CO}_{2}$ cost. There is a natural correlation however which comes to mind between oil, gas, and $\mathrm{CO}_{2}$ : this explaining factor is the economy. Macroeconomic conditions indeed influence all commodity markets (Caballero et al. (2008)). If declining oil prices do not reduce per se the $\mathrm{CO}_{2}$ cost, a recession reduces both oil demand and industrial activities, and hence $\mathrm{CO}_{2}$ emissions that reduce the demand for $\mathrm{CO}_{2}$ rights, and ultimately the $\mathrm{CO}_{2}$ price.

Of course, the full nature of the price and volatility interrelationships between the oil, gas, and $\mathrm{CO}_{2}$ markets needs to be assessed with adequate econometric tools. It is fair to assume that gas or oil prices may be affected by the EU allowance market, which makes a multivariate approach necessary. As shown by Hsu Ku (2008) for the major equity and currency markets in the US, Japan, and the UK, transmission effects between markets and obvious time-varying correlations may be adequately captured by Multivariate GARCH models (MGARCH). This econometric technique has also been recently applied by Leeves (2008) to the flow rates of US workers between employment and unemployment to investigate links between flow-rates volatilities. Both studies reveal that substantial links and adjustment dynamics may be uncovered using a multivariate econometric analysis, that we propose to adapt in this article to energy and emissions markets.

Compared to previous literature, we adopt a multivariate econometric framework which al-

\footnotetext{
${ }^{2} \mathrm{~A} \operatorname{GARCH}(p, q)$ model stands for a General Autoregressive Conditional Heteroskedasticity model of autoregressive order $p$ and moving average $q$.

${ }^{3}$ In a somewhat different setting, Kanen (2006) identifies brent prices as the main driver of natural gas prices which, in turn, affect power prices and ultimately $\mathrm{CO}_{2}$ prices. Bunn and Fezzi (2009) also identify econometrically that $\mathrm{CO}_{2}$ prices react significantly to a shock on gas prices in the short term.

${ }^{4} \mathrm{~A}$ disclaimer is necessary: only the European emissions market can be analysed and is analysed here.
} 
lows to analyze the time-varying correlations between the oil, gas and $\mathrm{CO}_{2}$ price series. While previous literature relied only on univariate GARCH models, the class of MGARCH models allows to capture the dynamics of variance and covariance overtime. We are primarily interested in identifying cross innovations and volatility spillover effects between energy and emissions markets. We also investigate the persistence of shocks overtime, and whether this persistence is more marked for own market innovations, or for cross markets innovations. The results obtained will thus be of particular importance for traders, financial institutions, and regulated utilities that lack a precise identification of correlations between energy and emissions markets for hedging and risk-management purposes.

As in Hsu Ku (2008), we use both Vector Autoregressive VAR and MGARCH models as part of our estimation strategy. Our study period goes from April 22, 2005 to December $15,2008^{5}$. Based on various specifications of multivariate GARCH models (BEKK, CCC, DCC $)^{6}$, we are able to highlight the transmission of price volatility among the three markets. Own volatility and cross volatility spillovers are significant for nearly all markets, indicating the presence of strong ARCH and GARCH effects. Strong own persistent volatility effects are also evident in all markets. Our main finding states that BEKK and constant-correlation MGARCH models are insufficient to assess the time-varying correlations between energy and emissions markets. The DCC MGARCH model provides the best results to examine the relationship between volatility and correlation. We find time-varying correlations in the order of $[-0.3 ; 0.3]$ between oil and gas, $[-0.05 ; 0.05]$ between oil and $\mathrm{CO}_{2}$, and $[-0.2 ; 0.2]$ between gas and $\mathrm{CO}_{2}$. To further elaborate on the meaning and the importance of the results, we can identify one major explaining factor behind such correlations between oil, gas, and $\mathrm{CO}_{2}$ prices: the macroeconomy.

The remainder of the article is organized as follows. Section 2 briefly reviews VAR and MGARCH modeling. Section 3 summarizes the data used. Section 4 presents the estimation results. Section 5 concludes.

\section{Review of Vector Autoregressive and Multivariate GARCH Models}

When modeling the interrelationships between oil, gas and $\mathrm{CO}_{2}$ prices, several choices arise in the empirical estimation strategy. The time-series may be studied independently as univariate time-series, each characterized by its own mean and autocovariance function. Alberola et al. (2008) and Oberndorfer (2009) have followed this approach, by including in the univariate

\footnotetext{
${ }^{5}$ i.e. from the start of $\mathrm{CO}_{2}$ trading on exchanges until the expiration date of the $\mathrm{CO}_{2}$ futures contract of maturity December 2008.

${ }^{6}$ As detailed below, BEKK stands for the Baba-Engle-Kraft-Kroner model, CCC for the constant conditional correlation model, and DCC for the dynamic conditional correlation model.
} 
time-series of $\mathrm{CO}_{2}$ prices exogenous regressors such as oil and gas prices.

Such an approach, however, fails to take into account the possible dependence between the time-series, which may be of great importance for understanding the observed values of the time-series. This perspective leads us to consider a vector of oil, gas and $\mathrm{CO}_{2}$ prices whose conditional covariance matrix evolves through time. Let us start with a brief review of VAR and MGARCH models.

\subsection{Vector Autoregressive models}

Following Sims (1980), a basic VAR model consists of a set of $K$ endogenous variables $y_{t}=$ $\left(y_{1 t}, \ldots, y_{k t}, \ldots, y_{K t}\right)$ for $k=1, \ldots, K$. A $\operatorname{VAR}(p)$ process may thus be defined as:

$$
y_{t}=A_{1} y_{t-1}+\ldots+A_{p} y_{t-p}+u_{t}
$$

where $A_{i}$ are $(K \times K)$ coefficient matrices for $i=1, \ldots, p$ and $u_{t}$ is a $K$-dimensional process with $E\left(u_{t}\right)=0$ and time-invariant positive definite covariance matrix $E\left(u_{t} u_{t}^{T}\right)=\sum_{u}$. For a given sample of $y_{1}, \ldots, y_{T}$ and sufficient pre-sample values $y_{-p+1}, \ldots, y_{0}$, the coefficients of a $\operatorname{VAR}(p)$ process can be estimated by OLS separately for each price series.

The main interest behind VAR modeling consists in generating stationary time-series with time invariant means, variances and covariance structure, given sufficient starting values. Besides, VAR models work quite well in many of the financial and econometric applications. Fitting a VAR model to energy and emissions markets thus appears as a natural extension of this methodology in line with our research question. Next, we recall various specifications of MGARCH.

\subsection{Multivariate GARCH models}

Consider $k$ time-series of return innovations $\left\{X_{i, t}, i=1, \ldots, k\right\}$. Stacking these innovations into a vector $\mathbf{X}_{t}$, we define $\sigma_{i i, t}=\operatorname{var}\left(X_{i, t} \mid \Im_{t-1}\right)$ and $\sigma_{i j, t}=\operatorname{cov}\left(X_{i, t}, X_{j, t} \mid \Im_{t-1}\right)$. We note $\Sigma_{t}=\sigma_{i j, t}$ the conditional variance-covariance matrix of all the time-series.

The main difficulty encountered with Multivariate GARCH modeling lies in finding a suitable system that describes the dynamics of $\Sigma_{t}$ parsimoniously. Besides, the multiple GARCH equation needs to satisfy the positive definiteness of $\Sigma_{t}$, which is a numerically difficult problem. Finally, the number of parameters to be estimated increases very rapidly as the dimension of the time-series increases, which can take a very long time during the numerical implementation. To address these questions, we detail below three parametric formulations for the structure of the conditional covariance matrices. 


\subsubsection{BEKK MGARCH models}

The first class of multivariate GARCH models that we study stems from the contributions of Bollerslev, Engle, and Wooldridge (1988), who provided with the VEC-GARCH model a straightforward extension of univariate GARCH models. We examine more particularly the following Baba-Engle-Kraft-Kroner (BEKK, Engle and Kroner (1995)) MGARCH model:

$$
H_{t}=C C^{\prime}+\sum_{j=1}^{q} \sum_{k=1}^{K} A_{k j}^{\prime} r_{t-j} r_{t-j}^{\prime} A_{k j}+\sum_{j=1}^{p} \sum_{k=1}^{K} B_{k j}^{\prime} H_{t-j} B_{k j}
$$

where $A_{k j}, B_{k j}$, and $C$ are $N \times N$ parameter matrices, and $C$ is lower triangular to ensure the positive definiteness of $H_{t}$. Note the BEKK model is covariance stationary if and only if the eigenvalues of $\sum_{j=1}^{q} \sum_{k=1}^{K} A_{k j} \otimes A_{k j}+\sum_{j=1}^{p} \sum_{k=1}^{K} B_{k j} \otimes B_{k j}$ are less than one in modulus, with $\otimes$ the notation for Kronecker products. Due to the computational burden involved by the estimation of a full $\mathrm{BEKK}$ model ${ }^{7}$, we restrict the number of parameters by implementing the following "diagonal BEKK" MGARCH model:

$$
H_{t}=C C^{\prime}+A^{\prime} r_{t-1} r_{t-1}^{\prime} A+D E\left[A^{\prime} r_{t-1} r_{t-1}^{\prime} A \mid \Im_{t-2}\right] D
$$

In eq(3), we now model the conditional variances and covariances of certain linear combinations of the vector of price returns $r_{t}$.

\subsubsection{MGARCH models}

The second class of multivariate GARCH models examined is based on the decomposition of the conditional covariance matrix into conditional standard deviations and correlations. In such Constant Conditional Correlation (CCC) MGARCH models (Bollerslev (1990)), the conditional correlation matrix is time-invariant and the conditional covariance matrix may be written as follows:

$$
H_{t}=D_{t} P D_{t}
$$

where $D_{t}=\operatorname{diag}\left(h_{1 t}^{1 / 2}, l \operatorname{dots}, h_{N t}^{1 / 2}\right)$ and $P=\left[\rho_{i j}\right]$ is positive definite with $\rho_{i i}=1, i=1, \ldots, N$. Off-diagonal elements of the conditional covariance matrix are computed as:

$$
\left[H_{t}\right]_{i j}=h_{i t}^{1 / 2} h_{j t}^{1 / 2} \rho_{i j}, i \neq j
$$

\footnotetext{
${ }_{7}$ As the number of parameters $(p+q) K N^{2}+N(N+1) / 2$ increases, it may be difficult to obtain convergence during the estimation.
} 
where $1 \leq i, j \leq N$. The conditional variances of $r_{i t}$ processes are similar to univariate $\operatorname{GARCH}(p, q)$ models:

$$
h_{t}=\omega+\sum_{j=1}^{q} A_{j} r_{t-j}^{2}+\sum_{j=1}^{p} B_{j} h_{t-j}
$$

with $\omega$ a $N \times 1$ vector, $A_{j}$ and $B_{j}$ diagonal $N \times N$ matrices, and $r_{t}^{2}=r_{t} \odot r_{t}$. When the conditional correlation matrix $P$ is positive definite and the elements of $\omega$ and the diagonal elements of $A_{j}$ and $B_{j}$ positive, the conditional covariance $H_{t}$ is positive definite.

\subsubsection{MGARCH models}

Due to the possibly overly restrictive assumption of constant conditional correlations, we consider a third class of multivariate GARCH models which attempts at making the conditional correlation in eq(4) time-varying:

$$
H_{t}=D_{t} P_{t} D_{t}
$$

According to Engle's (2002) Dynamic Conditional Correlation (DCC) MGARCH model, we introduce the following dynamic matrix process:

$$
Q_{t}=(1-a-b) S+a \epsilon_{t-1} \epsilon_{t-1}^{\prime}+b Q_{t-1}
$$

with $a$ and $b$ respectively positive and non-negative scalar parameters such that $a+b<1, S$ the unconditional correlation matrix of the standardized errors $\epsilon_{t}$, and $Q_{0}$ is positive definite. To produce valid correlation matrices, $Q_{t}$ needs to be re-scaled as follows:

$$
P_{t}=\left(I \odot Q_{t}\right)^{-1 / 2} Q_{t}\left(I \odot Q_{t}\right)^{-1 / 2}
$$

Having detailed the VAR and MGARCH modeling on which our empirical estimation strategy hinges, we present in the next section the data used.

\section{Data}

We study three time-series of oil, gas, and $\mathrm{CO}_{2}$ daily closing prices. Our study period goes from April 22, 2005 to December 15, 2008 which corresponds to a sample of 936 observations. The source of the data is the European Climate Exchange (ECX), Bloomberg and Reuters. 


\section{Insert Figure 1 about here}

Descriptive statistics for oil and gas raw price series, log-returns, VAR and MGARCH residuals may be found in Table 1. The distributional properties of the oil and gas raw price series appear non-normal. The oil and gas markets are positively skewed and since the kurtosis (or degree of excess) in both of these energy markets exceeds three, a leptokurtic distribution is indicated.

\section{Insert Table 1 about here}

Figure 1 presents the price development for the Zeebrugge natural gas next month, and NYMEX crude oil futures price series from April 22, 2005 to December 15, 2008. In November 2005 and September 2008, natural gas prices soared to $90 € / \mathrm{MWh}$, and steadily decreased afterwards to $40 € /$ MWh in February 2008 and December 2008. The brent price series peaked over $80 €$ /barrel from May to August 2008.

\section{$3.2 \quad \mathrm{CO}_{2}$ Price}

For $\mathrm{CO}_{2}$ prices, we use daily futures prices for the December 2008 contract traded in $€$ /ton of $\mathrm{CO}_{2}$ on ECX. In Figure 1, we observe that $2008 \mathrm{CO}_{2}$ futures prices convey a coherent price signal - around $20 € /$ ton of $\mathrm{CO}_{2}$ - throughout the historical available data during Phase II (2008-2012) of the EU ETS. The futures price development features a lower bound around $15 € /$ ton of $\mathrm{CO}_{2}$ in April 2007, and an upper bound around $35 € /$ ton of $\mathrm{CO}_{2}$ in November $2008^{8}$.

Descriptive statistics of the ECX futures contract of maturity December 2008 are presented in Table 1. We observe that the ECX December 2008 futures contract presents nonzero skewness and excess kurtosis 9 . These summary statistics also reveal a "fat tailed" leptokurtic distribution.

\section{Insert Figure 2 about here}

\footnotetext{
${ }^{8}$ Therefore, Phase II futures proved to be much more reliable than futures prices for delivery during Phase I (2005-2007) due to the banking restrictions enforced between 2007 and 2008 (Alberola and Chevallier (2009)).

${ }^{9}$ Note for a normally distributed random variable skewness is zero, and kurtosis is three.
} 
To sum up, none of the raw time-series under consideration may be approximated by the normal distribution. Oil, gas and $\mathrm{CO}_{2}$ log-returns are presented in Figure 2. In the next section, we present our estimation results.

\section{Estimation Results}

This section contains the estimation results for the VAR and MGARCH modeling of oil, gas, and $\mathrm{CO}_{2}$ prices, denoted by $\left(O I L_{t}, G A S_{t}, C O 2_{t}\right)^{\prime}$.

\subsection{VAR Results}

In this section, we conduct a preliminary data analysis by applying a $\operatorname{VAR}(p)$ process to the returns of each price series (see Hsu Ku (2008) for a similar approach). The stability of $\operatorname{VAR}(p)$ processes appears indeed useful to ensure that the variables under consideration are stationary. First, the raw time-series plots are shown in Figure 1. A visual inspection indicates nonstationarity in each of the series, so we proceed by taking differenced natural logs, which allows convenient interpretation by means of approximate percentage change. The time-series plots of log-returns, given in Figure 2, appear stationary. Second, to confirm this diagnostic, we conduct unit root tests by applying the Augmented Dickey-Fuller (ADF) test regressions. We use the oil, gas, and $\mathrm{CO}_{2}$ price series transformed into log-returns.

\section{Insert Table 2 about here}

The results of ADF tests are summarized in Table 2. These tests confirm that the original data are considered nonstationary. The oil, gas and $\mathrm{CO}_{2}$ price series are stationary when taken in logarithmic first-difference transformation. It can be concluded that all time-series are integrated of order one $(I(1))$. After taking this nonstationarity into account, we need to determine the optimal length for an unrestricted VAR (with a maximal lag number of eight).

\section{Insert Table 3 about here}

Those results are reported in Table 3. All criteria unambiguously point out an optimal lag order $p=1$. Thus, we choose the most parsimonious specification of a $\operatorname{VAR}(1)$ model. We can therefore proceed to fit a vector autoregressive model to the tri-variate log-returns of the time-series $\left(O I L_{t}, G A S_{t}, C O 2_{t}\right)^{\prime}$, which has a length of 936 observations. The $\operatorname{VAR}(p)$ model equation is:

$$
\left[\begin{array}{l}
O I L_{t} \\
G A S_{t} \\
C O 2_{t}
\end{array}\right]=\left[\begin{array}{l}
w_{1} \\
w_{2} \\
w_{3}
\end{array}\right]+\left[\begin{array}{lll}
\gamma_{1,1} & \gamma_{1,2} & \gamma_{1,3} \\
\gamma_{2,1} & \gamma_{2,2} & \gamma_{2,3} \\
\gamma_{3,1} & \gamma_{3,2} & \gamma_{3,3}
\end{array}\right]\left[\begin{array}{c}
O I L_{t-1} \\
G A S_{t-1} \\
C O 2_{t-1}
\end{array}\right]+\left[\begin{array}{c}
\epsilon_{1 t} \\
\epsilon_{2 t} \\
\epsilon_{3 t}
\end{array}\right]
$$


The estimated parameters and robust standard errors are given in Table 4, along with diagnostic tests. The VAR(1) model has 12 parameters, of which 3 are significant. Note that the gas variable is negatively impacted by its own lag, while the $\mathrm{CO}_{2}$ variable is positively impacted by the gas variable and its own lag at the $1 \%$ significance level. According to the diagnostic tests shown at the bottom of Table 4, there is no significant autocorrelation left in the residuals of this $\operatorname{VAR}(1)$ model $^{10}$. However, there is significant autocorrelation in the three series of squared residuals, which indicates the necessity to use a Multivariate GARCH model for further analysis.

\section{Insert Figure 3 about here}

Besides, OLS-CUSUM tests (based on cumulated sums of OLS residuals against a single-shift alternative, see Kramer and Ploberger (1992)) for the presence of structural changes in the components of the VAR(1) model are shown in Figure 3. We reject the null that the process should have a peak around the breakpoint for all time-series. For all variables, the empirical fluctuation processes stay safely within their bounds.

In the next step of our empirical strategy, we proceed by fitting a suitable MGARCH model to the residuals $\left(\epsilon_{1 t}, \epsilon_{2 t}, \epsilon_{3 t}\right)^{\prime}$ of the $\operatorname{VAR}(1)$ model for the oil, gas, and $\mathrm{CO}_{2}$ variables.

\subsection{MGARCH Results}

In this section, we discuss first some issues concerning the estimation of the MGARCH models presented in Section 2.2, and second we present the results obtained for each class of model.

\subsubsection{Estimation practicalities}

In the unrestricted BEKK MGARCH model, too large values of $K$ yield to an identification problem because several parameterizations yield the same representation of the model. To overcome these numerical difficulties, it is generally assumed that $p=q=K=1$ in the application of eq(2). Such restrictions may be found in Kroner and $\mathrm{Ng}$ (1998), where $B=\delta A$ and $\delta>0$ is a scalar. The estimation of the "diagonal BEKK" model for the three timeseries is carried out maximizing the log-likelihood, assuming that residuals are Gaussian white noise $^{11}$.

\footnotetext{
${ }^{10}$ To conserve space, the autocorrelation function $(\mathrm{ACF})$ for the residuals and squared residuals are not reproduced in the article, and may be obtained upon request to the authors.

${ }^{11}$ i.e. the log-likelihhod is computed on the basis of the normal distribution.
} 
The estimation of CCC MGARCH models offers on the contrary a computationally attractive parameterization. Besides the univariate GARCH equations, the number of parameters needing to be estimated is equal to $N(N-1) / 2$. Covariance stationarity is ensured if the roots of $\operatorname{det}\left(I-\sum_{j=1}^{q} A_{j} \lambda^{j}-\sum_{j=1}^{p} B_{j} \lambda^{j}\right)$ lie outside the unit circle.

In the DCC MGARCH model, positive definiteness of $H_{t}$ in eq(7) is ensured if the conditional correlation matrix $P_{t}$ is positive definite at each point in time, in addition to having welldefined conditional variances $h_{i t, i=1, \ldots, N}$. This leads again to computationally demanding estimation procedures, as the correlation matrix has to be inverted for each $t$ during every iteration.

In what follows, we set $p=1$ and $q=1$ for each class of MGARCH model. The BHHH algorithm (Berndt et al. (1974)) is used to produce quasi maximum likelihood parameter estimates and their corresponding asymptotic robust standard errors.

\subsubsection{BEKK MGARCH results}

Now we proceed to identifying a tri-variate BEKK $(1,1)$ MGARCH model to the residuals of the VAR(1) model. The model follows the equations:

$$
\epsilon_{t}=\mathrm{H}_{t}^{1 / 2} \nu_{t}, \quad \mathrm{H}_{t}=\mathrm{C}^{\prime} \mathrm{C}+\sum_{i=1}^{q} \mathrm{~A}_{i}^{\prime} \epsilon_{t-i} \epsilon_{t-i}^{\prime} \mathrm{A}_{i}+\sum_{j=1}^{p} \mathrm{~B}_{j}^{\prime} \mathrm{H}_{t-j} \mathrm{~B}_{j}
$$

with $\left(Z_{t}\right)=\left(W_{t}, X_{t}, Y_{t}\right)^{\prime}$ the time-series of oil, gas, and $\mathrm{CO}_{2}$ variables, $\mathrm{H}_{\mathrm{t}}$ the conditional covariance matrix of $Z_{t}, \operatorname{cov}\left(Z_{t} \mid \Im_{t-1}\right)=\mathrm{H}_{\mathrm{t}},\left\{\mathrm{C}, \mathrm{A}_{\mathrm{i}}, \mathrm{B}_{\mathrm{j}}\right\}$ the parameter matrices, $\nu_{t}$ a threedimensional white noise with covariance matrix $\operatorname{cov}(\nu)=\mathrm{I}_{n}$, and $\mathrm{I}_{n}$ the unity matrix of order $n$.

\section{Insert Table 5 about here}

The estimated parameters, together with their robust standard errors in parenthesis, are shown in Table 5. The BEKK $(1,1)$ MGARCH model has 27 parameters, of which 16 are significant. The maximum eigenvalue is 0.86901 . The coefficients for the variance-covariance equations are generally significant for own- and cross-innovations, and significant for ownand cross-volatility spillovers in the individual price series of oil, gas and $\mathrm{CO}_{2}$, indicating the presence of strong ARCH and GARCH effects. In evidence, $89 \%$ (8 out of 9 ) of the estimated ARCH coefficients, and 44\% (4 out of 9) of the estimated GARCH coefficients are significant at the $1 \%$ level.

Own-innovation spillovers in the energy and emissions markets are large and significant, indicating the presence of strong $\mathrm{ARCH}$ effects. The own-innovation spillover effects range 
from -0.55 for gas to 0.58 for $\mathrm{CO}_{2}$. In terms of cross-innovation effects, past innovations in most markets exert an influence on the other energy and/or emissions markets. For example, in the case of the $\mathrm{CO}_{2}$ market cross-innovations, the oil market is significant with a coefficient of -0.15 . The exception to the presence of cross-innovation effects is gas on the $\mathrm{CO}_{2}$ market. In the GARCH set of parameters, $44 \%$ of the estimated coefficients are significant. The lagged volatility spillover effects for oil, gas, and $\mathrm{CO}_{2}$ are equal to, respectively, $-0.84,-0.29$, and -0.64 . This means that past volatility shocks in each individual market have a greater effect on their own future volatility than the past volatility shocks in the other energy/emissions markets. In terms of cross-volatility for the GARCH parameters, the only significant parameter appears to be oil on the $\mathrm{CO}_{2}$ market. That is, past volatility shocks in the oil market have the greatest effect on the future volatility of the $\mathrm{CO}_{2}$ market. The latter result is in line with previous literature, which highlighted the predominant role of oil price changes in driving $\mathrm{CO}_{2}$ price changes. We are able to confirm this effect in a multivariate and dynamic econometric framework.

The sum of the ARCH and GARCH coefficients measures the overall persistence in each market's own volatility, i.e. $-0.45,0.84$, and -0.07 for the oil, gas and $\mathrm{CO}_{2}$ markets respectively. The cross-volatility spillover effect of the oil market on the $\mathrm{CO}_{2}$ market is equal to 0.22 . As a diagnostic check of the fitted model, the range of residuals is now closer to what we expect from a standard normal distribution, as the ACF plots for each time-series are contained within the critical values ${ }^{12}$. However, the ACF of the squared residuals between lags 9 and 14 clearly exhibit some autocorrelation. Thus, the diagnostic checks of the $\operatorname{BEKK}(1,1)$ MGARCH model suggest that the model may be misspecified with respect to the necessary white noise residuals properties ${ }^{13}$. We need to try and refine the trivariate GARCH model in order to remove the small number of remaining significant correlations in the ACFs of the standardized residuals ${ }^{14}$.

To this purpose, we detail in the next section the results obtained with constant conditional correlation and dynamic conditional correlation models.

\footnotetext{
${ }^{12}$ These plots are not reproduced in the article to conserve space, and may be obtained to the authors upon request.

${ }^{13}$ To make further visual assessment of the goodness of fit of the model, the interested reader may ask to the authors a graph of the standardized residuals. Note that while for an univariate GARCH standardized residuals are simply the model residuals divided by the conditional standard deviation, the standardized residuals for a multivariate GARCH are obtained by the whitening matrix transformation $\Sigma_{t}^{-1 / 2} \mathbf{Z}_{t}$. For a well-fitted multivariate GARCH model, this transformation produces standardized residual vectors that have an approximately diagonal conditional covariance matrix.

${ }^{14}$ Since the BEKK $(1,1)$ MGARCH model appears misspecified, we do not display the plots of the conditional standard deviations and correlations to conserve space.
} 


\subsubsection{MGARCH results}

We estimate below Bollerslev's (1990) constant-correlation model in which the conditional variances of $\left\{y_{t}\right\}, t=1, \ldots, T$ time-series with $K$ elements each so that $y_{t}=\left(y_{1 t}, \ldots, y_{K t}\right)^{\prime}$ follow a GARCH process, while the correlations are constant:

$$
\begin{aligned}
\sigma_{i t}^{2} & =\omega_{i}+\alpha_{i} \sigma_{i, t-1}^{2}+\beta_{i} y_{i, t-1}^{2}, \quad i=1, \ldots, K \\
\sigma_{i j t} & =\rho_{i j} \sigma_{i t} \sigma_{j t}, \quad 1 \leq i<j \leq K
\end{aligned}
$$

with $\omega_{i}, \alpha_{i}$, and $\beta_{i}$ nonnegative, $\alpha_{i}+\beta_{i}<1$ for $i=1, \ldots, K, \sigma_{i j t}$ the covariance elements, and $\Gamma=\left\{\rho_{i j}\right\}$ the correlation matrix positive definite. A tri-variate $\operatorname{GARCH}(1,1)$ model with constant-correlation is fitted to the $\operatorname{VAR}(1)$ residuals of oil, gas and $\mathrm{CO}_{2}$ variables. Compared to the $\operatorname{BEKK}(1,1) \mathrm{MGARCH}$, the $\mathrm{CCC}(1,1) \mathrm{MGARCH}$ does not exhibit autocorrelation, since the squared residuals remain in the range of the critical values ${ }^{15}$. Besides, the fitted model has resulted in smaller ACF values for the standardized residuals relative to the series observed. To provide further guidance in assessing the fit of the $\operatorname{CCC}(1,1)$ MGARCH model, the standardized residuals show that most, but not all, of the autocorrelation structure has been removed by the fitted $\mathrm{CCC}(1,1) \mathrm{MGARCH}$ model ${ }^{16}$. Nevertheless, the residuals of the $\mathrm{CCC}(1,1) \mathrm{MGARCH}$ model satisfy the required white noise properties, and useful interpretations may be derived from our estimates.

\section{Insert Figure 4 about here}

The time-varying standard deviations estimated from the CCC $(1,1)$ MGARCH model for the oil, gas and $\mathrm{CO}_{2}$ variables are shown in Figure 4.

\section{Insert Table 6 about here}

The results are summarized in Table 6 . The CCC $(1,1)$ MGARCH model has 12 parameters, of which 9 are significant. The last three rows of Table 6 show estimates of the correlation parameters. The other rows show parameter estimates of univariate $\operatorname{GARCH}(1,1)$ models for each time-series. As can be seen, most of the estimated univariate GARCH parameters, except the constant terms, are statistically significant and positive. The level of the ARCH coefficient, which represents the reaction to new information, is quite low. The value of $\alpha+\beta$ is close to one for each time-series, which suggests that the variance process is not integrated (Engle and Bollerslev (1986)). As for the correlation parameters, we observe that

\footnotetext{
${ }^{15} \mathrm{ACF}$ of residuals and squared residuals are not reproduced in the article to conserve space, and may be asked upon request to the authors.

${ }^{16}$ This figure is not reproduced in the article to conserve space, and may be asked upon request to the authors.
} 
the correlations across the three energy and emissions markets are quite low, all below 0.1. There is strong evidence (significance at the 1\% level) of time-varying correlations between the tri-variate time-series. Not surprisingly, we find evidence against constant correlations.

As highlighted in previous literature (Alberola et al. (2008), Oberndorfer (2009), Bunn and Fezzi (2009)), $\mathrm{CO}_{2}$ price changes are dependent, to a large extent, on price changes of other energy markets such as oil and gas. If these markets have low correlations, and/or their relationships are not stable overtime ${ }^{17}$, we would expect the correlations between the three time-series to be time-varying. This comment brings us to investigate in the next section the interrelationships between oil, gas and $\mathrm{CO}_{2}$ prices from a dynamic correlation perspective.

\subsubsection{MGARCH results}

For the ease of presentation, we re-state the $\operatorname{DCC}(m, n)$ MGARCH model estimated (Engle $(2002))$ :

$$
\begin{gathered}
h_{i, t}=\omega_{i}+\sum_{p=1}^{P_{i}} \alpha_{i_{p}} r_{i, t-p}^{2}+\sum_{q=1}^{Q_{i}} \beta_{i_{q}} h_{i, t-p} i=1, \ldots, k \\
Q_{t}=\left(1-\sum_{m=1}^{M} \alpha_{m}^{*}-\sum_{n=1}^{N} \beta_{n}^{*}\right) \bar{Q}+\sum_{m=1}^{M} \alpha_{m}^{*}\left(\epsilon_{t-m} \epsilon_{t-m}^{\prime}\right)+\sum_{n=1}^{N} \beta_{n}^{*} Q_{t-n} \\
R_{t}=\tilde{Q}_{t}^{-1} Q_{t} \tilde{Q}_{t}^{-1}
\end{gathered}
$$

with $\epsilon_{t}=D_{t}^{-1} r_{t}, \epsilon_{t} \sim N\left(0, R_{t}\right), \tilde{Q}_{t}$ a diagonal matrix containing the square root of the diagonal entries of $Q_{t}$, and $\bar{Q}_{t}$ the matrix of unconditional covariances. $\mathrm{Eq}(12)$ is a standard univariate GARCH model, and eq(13) is referred to as a $\operatorname{DCC}(m, n)$ model. We fit eq(12) and (13) to the $\operatorname{VAR}(1)$ residuals of oil, gas, and $\mathrm{CO}_{2}$ variables. As explained in Section 4.2.1, we choose to adopt the most parsimonious specification with $m=1$ and $n=1$. Similarly to the constant-correlation model, the ACF plots of residuals and squared residuals do not exhibit autocorrelation $^{18}$. It may be concluded that the residuals of the DCC $(1,1)$ MGARCH model satisfy the necessary white-noise properties.

\section{Insert Figure 5 about here}

In Figure 5, we can also look at the normal $Q-Q$ plots of the standardized residuals for all estimated models. We observe that the deviation from the normal distribution is highest in

\footnotetext{
${ }_{17}$ Alberola et al. (2008) highlight that the influence of other energy markets (such as oil and gas) on $\mathrm{CO}_{2}$ price changes varies depending on institutional events.

${ }^{18}$ These plots are not reproduced in the article to conserve space, and may be asked upon request to the authors.
} 
the VAR model. The $Q-Q$ plots for oil almost lie on a straight line in all MGARCH models, while gas seems to differ from the normal distribution. Compared to gas, the mismatch appears less pronounced for the $\mathrm{CO}_{2}$ variable in all MGARCH models.

Insert Table 7 about here

DCC $(1,1)$ MGARCH estimates are reported in Table 7. The DCC $(1,1)$ MGARCH model has 11 parameters, of which 7 are significant. As sensitivity tests, we notice the remarkable stability of the coefficients and robust standard error estimates between the $\operatorname{CCC}(1,1)$ and DCC $(1,1)$ MGARCH models. The correlation structure of the DCC $(1,1)$ MGARCH model has a clear interpretation: there is a non-constant interaction of the three time-series with respect to conditional correlation, and this correlation impacts current correlation with a lag of 1 . This interaction effect would be neglected if the three time-series of VAR residuals were modeled in isolation, each with a univariate GARCH model. Next, we reproduce Engle and Sheppard's (2001) test for the presence of dynamic correlation in the residuals of the DCC $(1,1)$ MGARCH model:

$$
\begin{aligned}
& H_{0}: R_{t}=\bar{R} \quad \forall t \in T \\
& H_{a}: \operatorname{vech}\left(R_{t}\right)=\operatorname{vech}(\bar{R})+\beta_{1} \operatorname{vech}\left(R_{t-1}+\beta_{2} \operatorname{vech}\left(R_{t}-1\right)+\ldots+\beta_{p} \operatorname{vech}\left(R_{t-1}\right)\right)
\end{aligned}
$$

Engle and Sheppard's (2001) $p$ value and $\chi^{2}$ statistic testing for the dynamic correlation between the oil, gas and $\mathrm{CO}_{2}$ residuals are presented in the last two rows of Table 7 . Under the null the constant and all of the lagged parameters in the model should be zero. Thus, we reject the null of a constant correlation in favor of a dynamic structure.

\section{Insert Figure 6 about here}

In Figure 6, we provide a visual representation of the dynamic correlations between the oil, gas and $\mathrm{CO}_{2}$ variables estimated from the $\mathrm{DCC}(1,1) \mathrm{MGARCH}$ model ${ }^{19}$. To allow direct comparison, the dashed lines in Figure 6 represent the estimated constant conditional correlations from the $\mathrm{CCC}(1,1) \mathrm{MGARCH}$ model. The constant-correlation model tends to bias (upward in the case of $\rho_{G A S, C O 2}$, downward in the case of $\rho_{\mathrm{OIL}, \mathrm{CO} 2}$ ) the actual correlations observed in the dynamic correlation model. The DCC MGARCH model thus provides a more accurate description of the dynamics of the correlations between the oil, gas, and $\mathrm{CO}_{2}$ variables overtime.

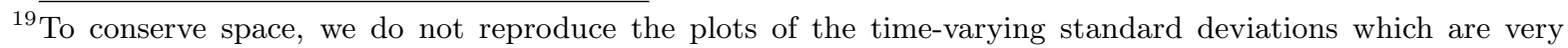
similar to the CCC $(1,1)$ MGARCH model, due to the stability of the coefficients estimated with the DCC $(1,1)$ MGARCH model.
} 
The values observed for $\rho_{O I L, G A S}$ are comprised between -0.3 and 0.3 , which represents a significantly higher bandwith than the value of -0.02 estimated in the $\mathrm{CCC}(1,1) \mathrm{MGARCH}$. The main reason behind this sharp difference between the constant and dynamic correlations models lie in the presence of two peaks in the dynamics of $\rho_{O I L, G A S}$ observed in August and September 2005. These peaks have also been observed in the raw price series, as commented in Section 3.1. Otherwise, $\rho_{O I L, G A S}$ oscillates around the value found in the constant correlation model.

$\rho_{\mathrm{OIL}, \mathrm{CO} 2}$ spans the range of values comprised between -0.05 and 0.05 , with a few peaks in the observed correlations. The constant correlation of -0.04 estimated with the $\operatorname{CCC}(1,1)$ MGARCH model lies outside of the interval where both series oscillates (around 0.01). This plot gives us a clear picture of the dynamic correlations behind the evolution of the oil and $\mathrm{CO}_{2}$ price series overtime.

As for $\rho_{G A S, C O 2}$, the correlation structure spans the range from nearly -0.2 to over 0.1 , which differs from the value of 0.018 found in the $\mathrm{CCC}(1,1)$ MGARCH model. Significant peaks may be found during the period going from April to October 2006, which corresponds to institutional developments during Phase I of the EU ETS ${ }^{20}$. The visual inspection of Figure 6 has overall confirmed the superiority of the DCC MGARCH model over the CCC MGARCH model to examine the contemporaneous relationships between volatility and correlation on energy and emissions markets. We may conclude that there is strong evidence of time-varying correlations among the selected oil, gas, and $\mathrm{CO}_{2}$ variables.

\section{Conclusion}

Previous studies on the interrelationships between energy (oil, gas) and emissions $\left(\mathrm{CO}_{2}\right)$ markets have focused on univariate GARCH models (Alberola et al. (2008), Oberndorfer (2009)). These articles identified oil and gas (among energy prices) as being the main drivers of the $\mathrm{CO}_{2}$ price (see also Bunn and Fezzi (2009) for structural interactions results). To take this analysis one step further, the goal of our article is to further analyze the co-movements of the oil, gas, and $\mathrm{CO}_{2}$ price series. Multivariate GARCH models appear as an adequate tool to fulfill such an objective (see Hsu Ku (2008) and Leeves (2008) for recent applications).

Compared to previous literature, we investigate the time-varying correlations of the energy and emissions markets in a multivariate modeling framework. Our econometric methodology consists in fitting various specifications of multivariate GARCH to the residuals of a vector autoregressive model for the three price series. Following a brief review of VAR and MGARCH

\footnotetext{
${ }^{20}$ Namely, the first verification of emissions occurred in April 2006 (Alberola et al. (2008)), while the European Commission announced banking restrictions between 2007 and 2008 in October 2006 (Alberola and Chevallier (2009))
} 
models, we have detailed the main interests for investigating dynamic correlations between energy and emissions markets. Then, we have detailed the daily data used for oil, gas, and $\mathrm{CO}_{2}$ prices from April 2005 to December 2008. After fitting a VAR model to the logreturns of the time-series, the observed squared residuals revealed significant autocorrelations in all time-series, indicating a further need for tri-variate MGARCH modeling. Hence, we investigated the interrelationships between the oil, gas, and $\mathrm{CO}_{2}$ markets by using three classes of MGARCH: BEKK models, constant conditional correlation (CCC) and dynamic conditional correlation (DCC) models.

The BEKK MGARCH model allows to identify own and cross volatility spillovers between energy and emissions markets. We also establish that past volatility shocks have a stronger effect on their own future volatility rather than on the other energy/emissions markets. However, we noticed that the squared residuals of the BEKK MGARCH models exhibit some autocorrelation, which suggests model misspecification. As for constant-correlation models, we find strong evidence of time-varying correlations between the oil, gas and $\mathrm{CO}_{2}$ price series. For this reason, we conclude that the CCC MGARCH model does not capture adequately the dependence between the conditional correlations of the oil, gas, and $\mathrm{CO}_{2}$ price series.

The class of DCC MGARCH model features white noise residuals properties, while reflecting the dynamic correlations overtime. It also uncovers clear interactions between the VAR residuals with respect to conditional correlation. These interactions impact the current correlation structure with a lag of one, and would have been neglected if the three time-series were modeled in isolation using univariate GARCH models. The estimates of time-varying correlations typically features values of $[-0.3 ; 0.3]$ between oil and gas, $[-0.05 ; 0.05]$ between oil and $\mathrm{CO}_{2}$, and $[-0.2 ; 0.2]$ between gas and $\mathrm{CO}_{2}$. The DCC MGARCH model may therefore be identified as being the most satisfactory.

Through this empirical analysis, we have been able to identify strong connections between energy and emissions markets. These results convey interesting applied economics insights, as they inform us about the dynamic correlations between oil, gas, and $\mathrm{CO}_{2}$ prices modeled jointly overtime. They may be used directly in the banking and finance industry, as well as by brokers for companies regulated by the EU ETS, to make informed hedging decisions. In extension of this work, an interesting area for future research lies in the investigation of the transmission of shocks on the term structure of the energy and emissions markets, as is usual for other financial markets (Christiansen (2000)). 
Alberola, E., Chevallier, J., 2009. European carbon prices and banking restrictions: Evidence from Phase I (2005-2007). The Energy Journal 30(3), 51-80.

Alberola, E., Chevallier, J., Chèze, B., 2008. Price drivers and structural breaks in European carbon prices 2005-2007. Energy Policy 36, 787-797.

Berndt, E.K., Robert, E.,Hall, B.H., Hausman, J.A., 1974. Estimation and Inference in Nonlinear Structural Models. Annals of Economic and Social Measurement 3; 653-665.

Bollerslev, T., 1990. Modelling the Coherence in the Short-Run Nominal Exchange Rates: A Multivariate Generalized ARCH Model. Review of Economics and Statistics 72, 498-505.

Bollerslev, T., Engle, R.F., Wooldridge, J.M., 1988. A Capital Asset Pricing Model with Time-Varying Covariances. The Journal of Political Economy 96, 116-131.

Bunn, D., Fezzi, C., 2009. Structural interactions of European carbon trading and energy prices. Journal of Energy Markets 2(4), 53-69.

Caballero R., Farhi E., Gourinchas, P., 2008. Financial Crash, Commodity Prices and Global Imbalances. Brookings Papers on Economic Activity 2, 1-55.

Christiansen, C., 2000. Macroeconomic Announcement Effects on the Covariance Structure of Government Bond Returns. Journal of Empirical Finance 7, 479-507.

Dickey, D.A., Fuller, W.A., 1981. Likelihood Ratio Statistics for Autoregressive Time Series with a Unit Root. Econometrica 49(4), 1057-1072.

Engle, R.F., Bollerslev, T., 1986. Modelling the persistence of conditional variances. Econometric Reviews 5, $1-50$.

EngLe, R.F., 2002. Dynamic Conditional Correlation: A Simple Class of Multivariate Generalized Autoregressive Conditional Heteroskedasticity Models. Journal of Business and Economic Statistics 20, 339-350.

Engle, R.F., Kroner, K.F., 1995. Multivariate Simultaneous Generalized ARCH. Econometric Theory 11, $122-150$

Engle, R.F., Sheppard, K., 2001. Theoretical and Empirical Properties of Dynamic Conditional Correlation Multivariate GARCH. NBER Working Paper 8554.

Hamilton, J.D., 1994. Time Series Analysis. Princeton University Press.

HsU KU, Y.H., 2008. Student- $t$ distribution based VAR-MGARCH: an application of the DCC model on international portfolio risk management. Applied Economics 40, 1685-1697.

Kanen J.L.M., 2006. Carbon Trading and Pricing. Environmental Finance Publications.

Kramer, W., Ploberger, W., 1992. The CUSUM Test with OLS Residuals. Econometrica 60, 271-285.

Kroner, K.F., NG, V.K., 1998. Modeling Asymmetric Comovements of Asset Returns. The Review of Financial Studies 11, 817-844.

LEEvES, G.D., 2008. Declining US output volatility and its effect on labour flow volatility: an MGARCH analysis. Applied Economics iFirst, 1-9.

OBERNDORfER, U., 2009. EU emission allowances and the stock market: evidence from the electricity industry. Ecological Economics 68, 1116-1126.

Sims, C.A., 1980. Macroeconomics and Reality. Econometrica 48(1), 1-48. 
Figure 1 $215 \times 279 \mathrm{~mm}(600 \times 600 \mathrm{DPI})$

Higure 1: Raw Price Series of NYMEX Crude Oil Futures, Zeebrugge Natural Gas Next Month, and ECX December $2008 \mathrm{CO}_{2}$ Futures from April 22, 2005 to December 15, 2008 Source: Reuters, Bloomberg and ECX
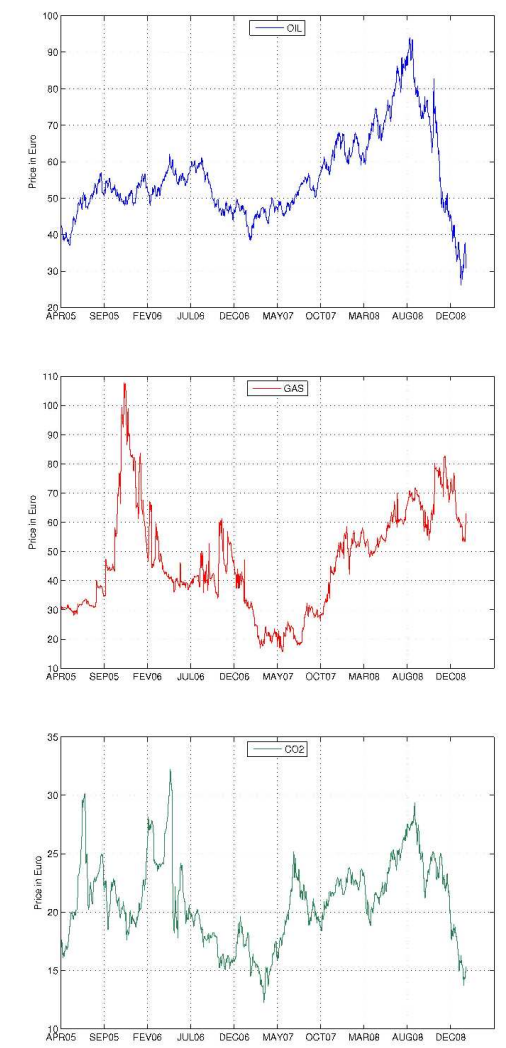

\section{(3)}




1
2
3
4
5
6
7
8
9
10
11
12
13
14
15
16
17
18
19
20
21
22
23
24
25
26
27
28
29
30
31
32
33
34
35
36
37
38
39
40
41
42
43
44
45
46
47
50
58
59
50
52
53
50
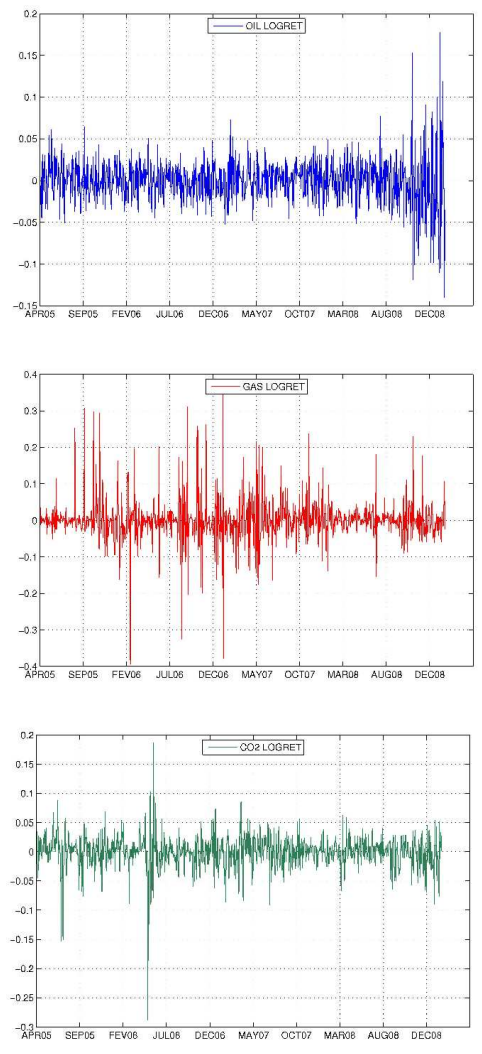

Figure 2: Log-returns of Oil, Gas, and $\mathrm{CO}_{2}$ Variables

Figure 2 $215 \times 279 \mathrm{~mm}(600 \times 600 \mathrm{DPI})$ 

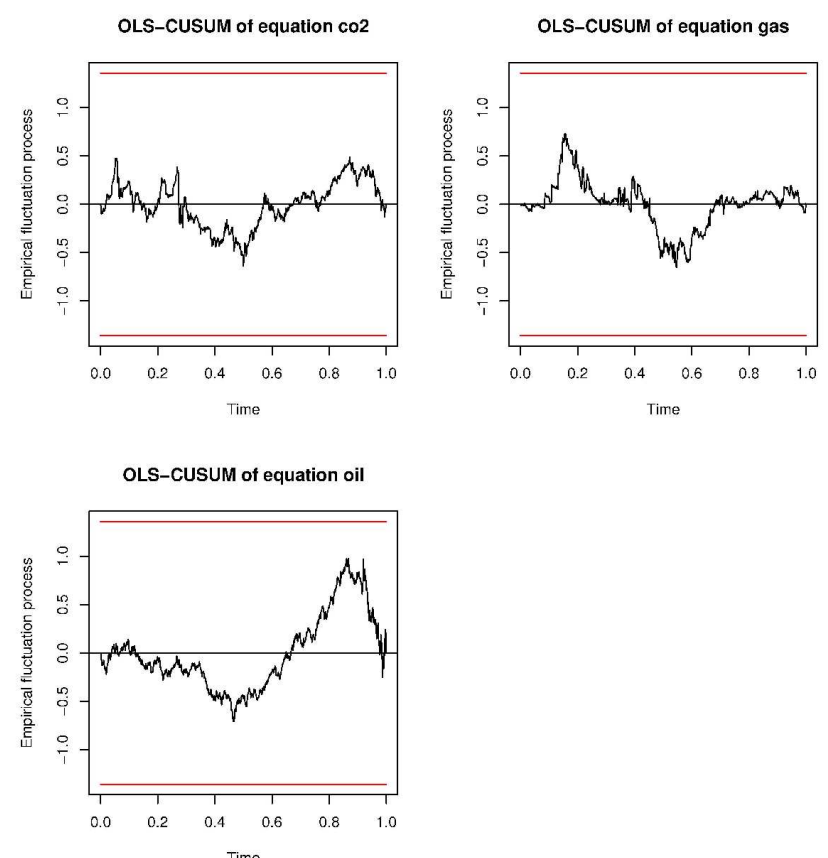

Figure 3: OLS CUSUM tests for the VAR(1) model with Oil, Gas and $\mathrm{CO}_{2}$ Variables

Figure 3 $215 \times 279 \mathrm{~mm}(600 \times 600 \mathrm{DPI})$ 
Figure 4 $215 \times 279 m m(600 \times 600$ DPI $)$ 

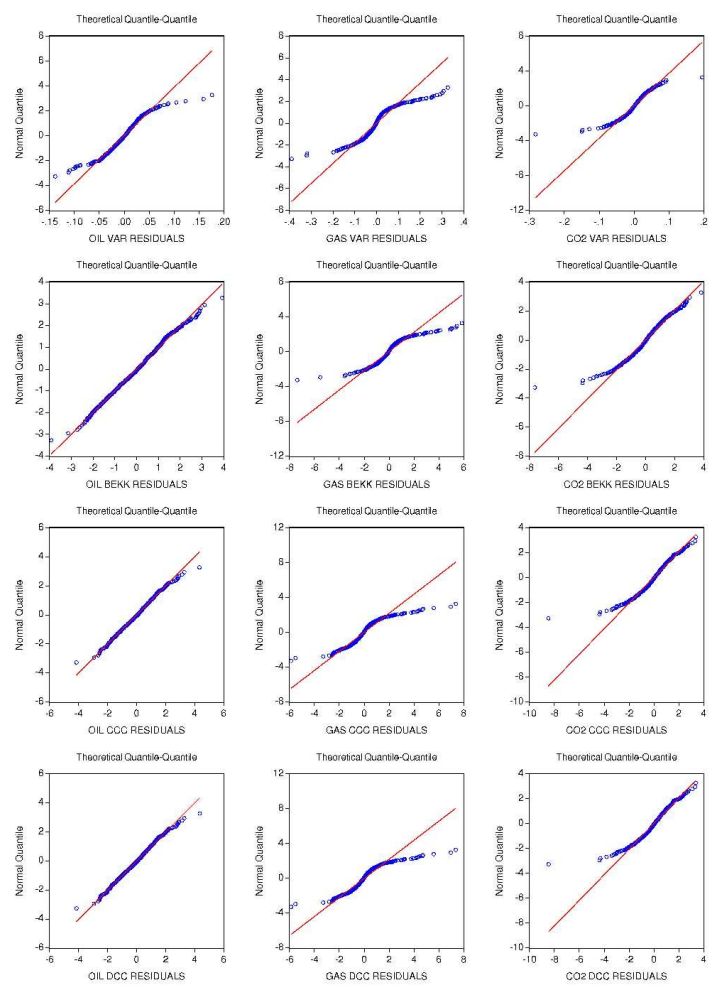

Figure 5: Normal $Q-Q$ plots of the standardized residuals for the $\operatorname{VAR}(1)$ (first row), BtKK $(1,1)$ MGARCH (second row), CCC(1,1) MGARCH (third row), DCC(1,1) MGARCH (fourth row) wit. the Oil (left pancl), Gas (middle panel), and $\mathrm{CO}_{2}$ (right panel) Variables

Note: Normal $Q-Q$ plot stands for the quantiles of the standardized residuals plotted against the quantiles of the normal distribution.

Figure 5 $215 \times 279 \mathrm{~mm}(600 \times 600 \mathrm{DPI})$ 
Figure 6

Higure 6: Dynamic Conditional Correlations between Oil and Gas (top panel), Oil and $\mathrm{CO}_{2}$ (middle pancl), Gas and $\mathrm{CO}_{2}$ (bottom pancl) cstimated with the DCC $(1,1)$ MGARCH model

Note: In each panel, the dashed line is the estimated constant conditional correlation from the CCC $(1,1)$ MGARCH model.
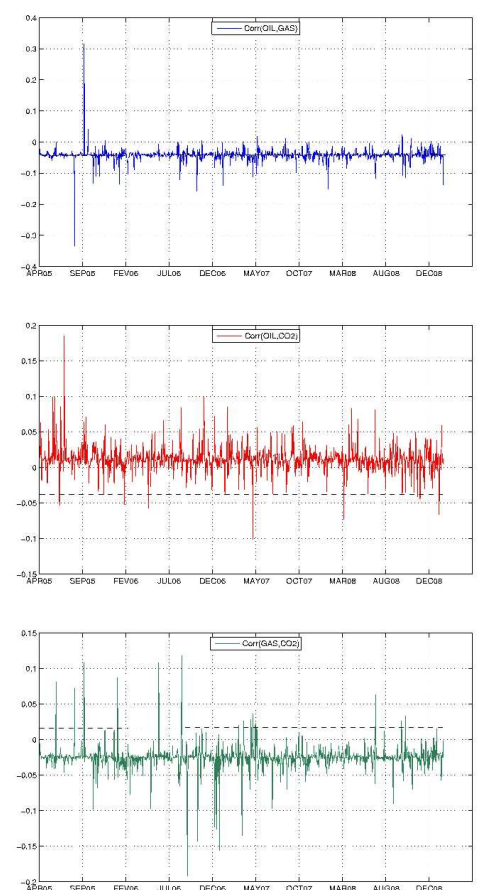

$\mathrm{mm}(600 \times 600 \mathrm{DPI})$ 


\begin{tabular}{lcclllll}
\hline Variable & Mean & Median & Max & Min & $\begin{array}{l}\text { Std. } \\
\text { Dev. }\end{array}$ & Skew. & Kurt. \\
\hline Raw Price Series & & & & & & & \\
Oil & 55.7279 & 53.1892 & 93.9841 & 26.2558 & 11.9011 & 0.8585 & 3.6833 \\
Gas & 46.6878 & 44.3250 & 107.7500 & 15.7200 & 17.8437 & 0.5299 & 3.0022 \\
$\mathrm{CO}_{2}$ & 20.9298 & 20.9000 & 32.2500 & 12.2500 & 3.5804 & 0.2084 & 2.7831 \\
\hline Log-Returns & & & & & & & \\
Oil & -0.0003 & 0.0004 & 0.1776 & -0.1401 & 0.0268 & 0.0988 & 8.4889 \\
Gas & 0.0008 & -0.0014 & 0.3590 & -0.3949 & 0.0603 & 0.5472 & 13.2876 \\
$\mathrm{CO}_{2}$ & -0.0001 & 0.0012 & 0.1865 & -0.2882 & 0.0287 & -1.3195 & 17.7714 \\
\hline
\end{tabular}

Table 1: Summary Statistics

Note: Oil refers to NYMEX crude oil, Gas to Zeebrugge Natural Gas Next Month, and $\mathrm{CO}_{2}$ to ECX December 2008 futures price series. Std.Dev. stands for Standard Deviation, Skew. for Skewness, and Kurt. for Kurtosis. The number of observations is 936 . 


\begin{tabular}{lllllll}
\hline Variable & $\begin{array}{l}\text { Deterministic } \\
\text { Terms }\end{array}$ & Lags & $\begin{array}{l}\text { Test } \\
\text { Value }\end{array}$ & \multicolumn{2}{l}{ Critical Values } & \\
& & & & $1 \%$ & $5 \%$ & $10 \%$ \\
\hline Oil & constant, trend & 2 & -18.0672 & -3.96 & -3.41 & -3.12 \\
O $i l$ & constant & 1 & -23.4714 & -3.43 & -2.86 & -2.57 \\
Gas & constant, trend & 2 & -20.0859 & -3.96 & -3.41 & -3.12 \\
$\Delta$ Gas & constant & 1 & -24.4663 & -3.43 & -2.86 & -2.57 \\
$\mathrm{CO}_{2}$ & constant, trend & 2 & -16.406 & -3.96 & -3.41 & -3.12 \\
$\mathrm{CO}_{2}$ & constant & 1 & -19.9418 & -3.43 & -2.86 & -2.57 \\
\hline
\end{tabular}

Table 2: ADF Tests for Oil, Gas and $\mathrm{CO}_{2}$ Variables

Note: Oil refers to NYMEX crude oil, Gas to Zeebrugge Natural Gas Next Month, and $\mathrm{CO}_{2}$ to ECX December 2008 futures price series. The critical values reported are from Dickey and Fuller (1981) and Hamilton (1994). The number of observations is 936 . 


\begin{tabular}{lllllllll}
\hline Lag & 1 & 2 & 3 & 4 & 5 & 6 & 7 & 8 \\
\hline$A I C(n)$ & -1.997933 & -1.997209 & -1.996408 & -1.994872 & -1.995287 & -1.994975 & -1.993828 & -1.992055 \\
$H Q(n)$ & -1.99450 & -1.992437 & -1.989847 & -1.986521 & -1.985147 & -1.983045 & -1.980109 & -1.976545 \\
$S C(n)$ & -1.990114 & -1.984699 & -1.979207 & -1.972980 & -1.968704 & -1.963700 & -1.957862 & -1.951397 \\
$F P E(n)$ & 0.000210 & 0.000212 & 0.000214 & 0.000217 & 0.000216 & 0.000217 & 0.000219 & 0.000223 \\
\hline
\end{tabular}

\begin{tabular}{lllllll}
\hline \multicolumn{1}{l}{ Diagnostic } & Tests & \multicolumn{1}{l}{} \\
\hline Lag & $Q_{1} 6$ & $p$ value & $J B_{4}$ & $p$ value & $M A R C H_{5}$ & $p$ value \\
$p=1$ & 165.1727 & 0.03965 & 13208.33 & 0.00001 & 481.9319 & 0.00001 \\
\hline
\end{tabular}

Table 3: VAR Optimal Lag Length Determination for Oil, Gas and $\mathrm{CO}_{2}$ Variables

Note: Oil refers to NYMEX crude oil, Gas to Zeebrugge Natural Gas Next Month, and $\mathrm{CO}_{2}$ to ECX December 2008 futures price series. $A I C(n)$ refers to the Akaike Information Criterion for a lag of order $n, H Q(n)$ refers to the Hannan-Quinn Criterion for a lag of order $n$, $S C(n)$ refers to the Schwarz Criterion for a lag of order $n$, and FPE $n)$ refers to the Final Prediction Criterion for a lag of order $n$. The number of observations is 936. Diagnostic tests are provided for the optimal lag length $p=1$. $Q_{16}$ refers to the Ljung-Box-Pierce Portmanteau Test $Q$ Statistic with a maximal lag of order $16, J B_{4}$ is the Jarque-Berra Normality Tests Statistic for a maximal lag of order 4 , and $\mathrm{MARCH}_{5}$ is the Multivariate ARCH Test Statistic for a maximal lag of order 5. 


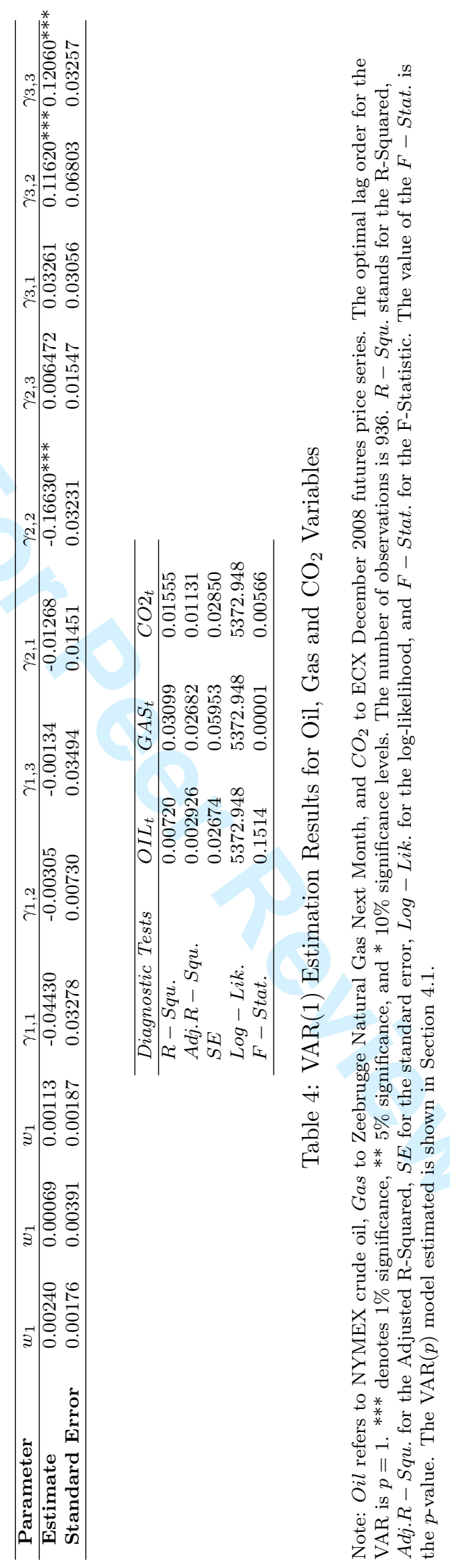




\begin{tabular}{|c|c|c|c|}
\hline \multirow[t]{2}{*}{ Parameter } & \multicolumn{3}{|l|}{ Estimate } \\
\hline & Oil & Gas & $\mathrm{CO}_{2}$ \\
\hline \multirow[t]{2}{*}{$\mathrm{C}_{O I L}$} & $-0.00910^{* * *}$ & $0.01089^{* * *}$ & 0.00001 \\
\hline & $(0.00138)$ & $(0.00613)$ & $(0.00001)$ \\
\hline \multirow{2}{*}{$\mathrm{C}_{G A S}$} & 0.00001 & $-0.04645^{* * *}$ & 0.00001 \\
\hline & $(0.00001)$ & $(0.00367)$ & $(0.00001)$ \\
\hline \multirow{2}{*}{$\mathrm{C}_{\mathrm{CO}_{2}}$} & 0.00083 & $0.01069^{* * *}$ & $-0.01481^{* * *}$ \\
\hline & $(0.00141)$ & $(0.00551)$ & $(0.00144)$ \\
\hline \multirow[t]{2}{*}{$\mathrm{A}_{O I L}$} & $0.38894^{* * *}$ & $0.18887^{* *}$ & $-0.14831^{* * *}$ \\
\hline & $(0.03606)$ & $(0.10386)$ & $(0.04072)$ \\
\hline \multirow[t]{2}{*}{$\mathrm{A}_{G A S}$} & $0.04024^{* * *}$ & $-0.54739^{* * *}$ & 0.03205 \\
\hline & $(0.01798)$ & $(0.06579)$ & $(0.02130)$ \\
\hline \multirow{2}{*}{$\mathrm{A}_{C O_{2}}$} & $0.01986^{* * *}$ & $0.23559 * * *$ & $0.57486^{* * *}$ \\
\hline & $(0.03490)$ & $(0.09673)$ & $(0.04516)$ \\
\hline \multirow[t]{2}{*}{$\mathrm{B}_{O I L}$} & $-0.83827^{* * *}$ & -0.00119 & $-0.08685^{* * *}$ \\
\hline & $(0.02893)$ & $(0.09296)$ & $(0.03915)$ \\
\hline \multirow[t]{2}{*}{$\mathrm{B}_{G A S}$} & -0.04919 & $-0.29449^{* * *}$ & -0.06569 \\
\hline & $(0.03600)$ & (0.13907) & $(0.04264)$ \\
\hline \multirow[t]{5}{*}{$\mathrm{B}_{C O_{2}}$} & 0.02625 & -0.06593 & $-0.64418^{* * *}$ \\
\hline & $(0.03283)$ & $(0.111374)$ & $(0.04679)$ \\
\hline & Diagnostic & & \\
\hline & $A I C$ & -6399.865 & \\
\hline & Eig. & 0.86901 & \\
\hline
\end{tabular}

Table 5: $\operatorname{BEKK}(1,1)$ MGARCH Estimates for Oil, Gas and $\mathrm{CO}_{2}$ Variables

Note: Oil refers to NYMEX crude oil, Gas to Zeebrugge Natural Gas Next Month, and $\mathrm{CO}_{2}$ to ECX December 2008 futures price series. Robust standard errors in parentheses. ${ }^{* * *}$ indicates $1 \%$ significance, ${ }^{* *} 5 \%$ significance, and $* 10 \%$ significance levels. The number of observations is 936. AIC is the Akaike Information Criterion. Eig. is the maximum eigenvalue. The $\operatorname{BEKK}(p, q)$ MGARCH model estimated is shown in Section 4.2.2. 


\begin{tabular}{ll}
\hline Parameter & \multicolumn{1}{c}{ Estimate } \\
\hline \multicolumn{2}{c}{ GARCH parameters } \\
$\omega_{O I L}$ & 0.0001 \\
& $(0.0001)$ \\
$\alpha_{O I L}$ & $0.1144^{* * *}$ \\
& $(0.0002)$ \\
$\beta_{O I L}$ & $0.8557^{* * *}$ \\
& $(0.0004)$ \\
$\omega_{G A S}$ & 0.0001 \\
& $(0.0001)$ \\
$\alpha_{G A S}$ & $0.0404^{* * *}$ \\
& $(0.0001)$ \\
$\beta_{G A S}$ & $0.9458^{* * *}$ \\
& $(0.0002)$ \\
$\omega_{C O_{2}}$ & 0.0001 \\
& $(0.0001)$ \\
$\alpha_{C O}$ & $0.2507^{* * *}$ \\
& $(0.0081)$ \\
$\beta_{C O_{2}}$ & $0.6942^{* * *}$ \\
& $(0.0059)$ \\
\hline Correlation & Parameters \\
$\rho_{O I L, G A S}$ & $-0.0243^{* * *}$ \\
& $(0.0001)$ \\
$\rho_{O I L, C O_{2}}$ & $-0.0398^{* * *}$ \\
$\rho_{G A S, C O_{2}}$ & $(0.0001)$ \\
& $0.0176^{* * *}$ \\
\hline Log - Lik. & $(0.0003)$ \\
\hline & 5671.3939 \\
\hline
\end{tabular}

Table 6: $\mathrm{CCC}(1,1)$ MGARCH Estimates for Oil, Gas and $\mathrm{CO}_{2}$ Variables

Note: Oil refers to NYMEX crude oil, Gas to Zeebrugge Natural Gas Next Month, and $\mathrm{CO}_{2}$ to ECX December 2008 futures price series. Robust standard errors in parentheses. ${ }^{* * *}$ indicates $1 \%$ significance, ${ }^{* *} 5 \%$ significance, and $* 10 \%$ significance levels. The number of observations is 936 . The $\mathrm{CCC}(p, q)$ MGARCH model estimated is shown in Section 4.2.3. 


\begin{tabular}{ll}
\hline Parameter & Estimate \\
\hline GARCH parameters \\
$\omega_{O I L}$ & 0.0001 \\
& $(0.0001)$ \\
$\alpha_{O I L}$ & $0.1144^{* * *}$ \\
& $(0.0002)$ \\
$\beta_{O I L}$ & $0.8557^{* * *}$ \\
& $(0.0004)$ \\
$\omega_{G A S}$ & 0.0001 \\
& $(0.0001)$ \\
$\alpha_{G A S}$ & $0.0404^{* * *}$ \\
& $(0.0001)$ \\
$\beta_{G A S}$ & $0.9458^{* * *}$ \\
& $(0.0002)$ \\
$\omega_{C O_{2}}$ & 0.0001 \\
& $(0.0001)$ \\
$\alpha_{C O_{2}}$ & $0.2507^{* * *}$ \\
& $(0.0081)$ \\
$\beta_{C O_{2}}$ & $0.6942^{* * *}$ \\
& $(0.0059)$ \\
\hline Correlation Parameters \\
$\alpha_{1}^{*}$ & $0.0190^{* * *}$ \\
$\beta_{1}^{*}$ & $(0.0003)$ \\
& 0.0001 \\
\hline Log- Lik. & $(0.0096)$ \\
ES p value & 5671.6345 \\
ES $\chi^{2}$ stat & 0.0333 \\
\hline & 0.9835 \\
&
\end{tabular}

Table 7: DCC $(1,1)$ MGARCH Estimates for Oil, Gas and $\mathrm{CO}_{2}$ Variables

Note: Oil refers to NYMEX crude oil, Gas to Zeebrugge Natural Gas Next Month, and $\mathrm{CO}_{2}$ to ECX December 2008 futures price series. Robust standard errors in parentheses. ${ }^{* * *}$ indicates $1 \%$ significance, ${ }^{* *} 5 \%$ significance, and $* 10 \%$ significance levels. The number of observations is 936. ES p value and ES $\chi^{2}$ stat are Engle and Sheppard's (2001) dynamic correlation tests statistics for a maximum lag of order 1. The DCC $(m, n)$ MGARCH model estimated is shown in Section 4.2.4. 